\section{SOI: 1.1/TAS DOI: 10.15863/TAS International Scientific Journal Theoretical \& Applied Science}

p-ISSN: 2308-4944 (print) e-ISSN: 2409-0085 (online)

Year: $2016 \quad$ Issue: $7 \quad$ Volume: 39

Published: $30.07 .2016 \quad$ http://T-Science.org

SECTION 9. Chemistry and chemical technology.
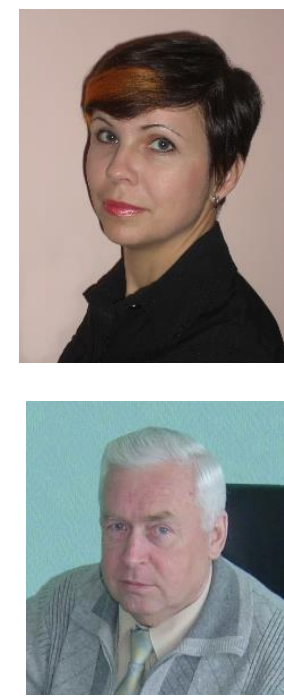

Elena Vorobyova

Canditate of Chemistry,

associate professor,

Chair of Chemistry in Skaryna

Gomel State University

Gomel, Belarus

Tel./fax: +375 232 601-403

evorobyova@gsu.by

Dmitry Lin

Doctor of Technical Sciences, professor,

Chair of General Physics in Skaryna

Gomel State University

Gomel, Belarus

Tel./Fax: +375 232579707

nis@gsu.by

\title{
SOME FEATURES OF THE PHYSICAL BEHAVIOR OF IRGANOX 1010 USED FOR THERMAL OXIDATIVE STABILIZATION OF POLYETHYLENE
}

\begin{abstract}
The Irganox 1010 phenolic antioxidant introduced into a polyethylene powder from a solution in acetone followed by thermal pressing of the sample in the form of a film is only partially fixed in IR spectra of the polymer. A significant part of the antioxidant additive remains "invisible" in the IR spectra, since it is in the disperse form and is stationed in former inter-powder contact boundaries. The concentration of the antioxidant adsorbed by the polymer increases in samples pressing time and in the duration of their oxidative treatment in air. As the antioxidant diffusively proceeds into the polymer melt, there is a decrease in a relative proportion of hydroxyl groups, which indicates the expenditure of the inhibitor. It is found that at temperatures below the polymer melting point, the hydroxyl groups of the antioxidant may be both free and bound by hydrogen bonds. When transferring the polymer into a melt, the intra- and intermolecular bonds of the antioxidant are largely destructed. This process is reversible: when the polymer is transferred back from a melt into a solid state, the hydrogen bonds are restored again.

Key words: polyethylene melt, IR spectra, antioxidant solution, Irganox 1010, hydrogen bonds, hydroxyl groups concentration, carbonyl groups concentration.

Language: Russian

Citation: Vorobyova EV, Lin DG (2016) SOME FEATURES OF THE PHYSICAL BEHAVIOR OF IRGANOX 1010 USED FOR THERMAL OXIDATIVE STABILIZATION OF POLYETHYLENE. ISJ Theoretical \& Applied Science, 07 (39): 17-27.

Soi: http://s-o-i.org/1.1/TAS-07-39-4 Doi: crossef http://dx.doi.org/10.15863/TAS.2016.07.39.4

\section{НЕКОТОРЫЕ ОСОБЕННОСТИ ФИЗИЧЕСКОГО ПОВЕДЕНИЯ ИРГАНОКСА 1010, ИСПОЛЬЗУЕМОГО ДЛЯ ТЕРМООКИСЛИТЕЛЬНОЙ СТАБИЛИЗАЦИИ ПОЛИЭТИЛЕНА}

Аннотация: Фенольный антиоксидант ирганокс 1010, вводимый в порошок полиэтилена из раствора в ацетоне с последующим термическим прессованием образца в виде пленки, лишь частично фиксируется 8 ИК-спектрах полимера. Значительная часть антиокислительной добавки остается «невидимой»в ИКспектрах, так как она находится в дисперсном виде и дислочируется в местах бывших грании, межпорошкового контакта. Концентрация сорбированного полимером антиоксиданта нарастает с увеличением времени прессования образиов и продолжстельности их окислительной обработки на воздухе. При этом в ходе диффузионного поступления антиоксиданта в расплав полимера происходит снижение относительной доли гидроксильных групп, что свидетельствует о расходовании ингибитора. Установлено, что при температурах ниже плавления полимера, гидроксильные группы антиоксиданта могут быть как свободными, так и связанными водородными связями. При переводе полимера в расплав внутри- и межмолекулярные водородные связи антиоксиданта в значительной мере разрушаются. Этот
\end{abstract}


проиесс носит обратимый характер - при обратном переводе полимера из расплава в твердое состояние водородные связи вновь восстанавливаются.

Ключевье слова: расплав полиэтилена, ИК-спектры, растворение антиоксиданта, ирганокс 1010, водородные связи, концентрация гидроксильных групп, концентрация карбонильных групп.

\section{Введение}

Из-за низкой термоокислительной стойкости полимерные материалы в чистом виде, как правило, не используются. Поэтому основным принципом антиокислительной защиты полимеров является введение в них модифицирующих добавок - антиоксидантов (сокращенно АО), которые вмешиваются в механизм окислительных превращений, подавляя зарождение и уменьшая длину цепей окисления, акцентируя катализатор и т.д. [1, 2].

Эффективность в использовании АО определяется сочетанием их физических и химических свойств, перечень которых проистекает из комплекса требований, предъявляемых к ингибитору: максимально равномерное распределение в объеме полимера, особая химическая структура и оптимальная концентрация в образце, совместимость с полимерной матрицей, диффузионная подвижность, летучесть, возможность восстановления химической структуры и повторного участия в подавлении окислительных превращений, сочетание с другими веществами с целью реализации одного из видов синергизма и др. $[1,2]$.

В соответствии с проявлением АО тех или иных свойств, различают их физическое и химическое поведение. Физическое поведение АО является основным фактором, влияющим на его эффективность $[1,3]$. Оно включает в себя распределение АО в объеме образца, миграционную подвижность [4-7], растворимость $[5,8]$, экссудацию (exudation) или выпотевание $[9,10]$, волатильность (volatility) или летучесть [11], испаряемость в атмосферу [12,13], вымываемость водой и технологическими жидкостями $[14,15]$, выщелачивание и даже дополнительные потери АО при механических воздействиях на полимер [16].

От АО в первую очередь требуется максимально равномерное распределение в объеме полимера [6]. Отметим сразу, что добиться этого невозможно из-за молекулярной неоднородности полимерного материала. Исследователи [1] выделяют в полимерах три уровня неоднородностей: анизотропию на молекулярном уровне, топологическую и структурную (морфологическую) неоднородности. $\mathrm{AO}, \quad$ являющиеся низкомолекулярными веществами, как правило, локализуются в аморфных областях полимеров. В полимерных кристаллитах они либо не растворяются, либо растворяются крайне ограничено $[17,18]$. Поэтому при формировании кристаллитной структуры на стадии охлаждения расплава полимера происходит вытеснение АО на периферию возникающих надмолекулярных образований, и они локализуются в аморфной зоне образца. По мнению многих исследователей антиокислительные добавки дислоцируются в основном в межфибриллярных участках, внутри сферолитов и межсферолитных промежутках. Аналогичное положение занимает и кислород при его растворении и диффузионном перемещении в полимерах [1]. Можно ожидать, что при обратном переводе полимера в расплав происходит поступление АО в аморфные зоны образца, которые раньше были кристаллитами. По сути, этот вопрос в литературе не исследован.

C учетом особенностей топологической структуры полимеров зарубежными исследователями [19] была предложена модель двойной сорбции низкомолекулярных веществ, в том числе и АО. У этой модели одна часть поглощенного вещества образует истинный раствор в аморфных зонах образца, вторая же часть сорбента достаточно прочно фиксируется в так называемых центрах сорбции. А.П.Марьин в своих работах, например, в [20] рассматривает сорбцию низкомолекулярных веществ полимерами как двухстадийный процесс: вначале образуется раствор сорбента, а затем растворенное вещество обратимо сорбируется центрами сорбции, существующими в полимере. Между количествами растворенных молекул сорбента и иммобилизованных молекул, находящимися в центрах сорбции, существует динамическое равновесие. Заметим, что неравномерность в распределении АО приводит к преждевременному окислению полимера в локальных зонах образца, что в свою очередь вызывает ускоренное расходование ингибитора и сокращает срок службы полимерных изделий.

Предельное количество АО, которые может быть растворено в аморфной фазе и поглощено центрами сорбции характеризуется термодинамической величиной, называемой концентрацией насыщения. Если введенное в полимер количество $\mathrm{AO}$ превышает концентрацию насыщения, то избыточная часть антиокислительной добавки может выпотевать на поверхность образца и далее испаряться в атмосферу или вымываться технологическими средами. Примерный уровень сорбционного поглощения АO полимерами составляет примерно $10^{-2} \%$ масс., что существенно ниже концентраций этих веществ, обычно 
используемых для окислительной защиты (чаще диапазон 0,1-0,5 \% масс.). Понятно, что при такой дозировке вводимого АО всегда неизбежны и значительны его физические потери. Еще в 70 гг. прошлого века в своей работе [9] Н.Bair приводит данные свидетельствующие, что в результате трехсуточного хранения при $70^{\circ} \mathrm{C}$ полимерных пленок, содержащих фенольный АО (использовался 4,4' -тио-бис(3-метил-6третбутил-фенол)), около $70 \%$ добавки выпотевает. Естественно, что это значительно сокращает срок службы пленок.

Сложным и дискуссионным продолжает оставаться вопрос о роли диффузии АО в проявлении им стабилизационной эффективности. С одной стороны, считается, что для того, чтобы дезактивировать образующие полимерные радикалы, нужно максимально быстро их нейтрализовать, то есть молекулы АО должны обладать достаточной диффузионной подвижностью $[6,8]$. АO с высоким коэффициентом диффузии более равномерно распределяется в полимере и имеет возможность быстро поступать в зону реакции окисления. Благодаря этому они являются более эффективными по сравнению с АО с низким коэффициентом диффузии. С другой стороны, высокий коэффициент диффузии неизбежно приводит к физическим потерям АО и их перераспределению среди других компонентов материала. Здесь следует учитывать, что по мере расходования растворенного АО на его место поступают молекулы добавки, находящиеся ранее в центрах сорбции.

В образцах ингибированного полимера могут заранее образовываться значительные градиентные перепады концентрации АО. Эти перепады возникают как на стадии получения изделий, так при их эксплуатации. Именно причиной образования градиентных перепадов являются низкий или, наоборот, высокий коэффициент диффузии АО в полимере. Например, из-за потерь АО при испарении в атмосферу или вымывании средой в поверхностном слое образца возникает недостаток АО. В результате реализуется диффузионный режим окисления и поступающий в полимер кислород расходуется ускоренно и вглубь образца не проникает. Для глубинных слоев полимера возникает своеобразный защитный эффект, хотя в поверхностном слое идет интенсивное окислительное разрушения материала. Однако, если для защиты такого образца в его поверхностный слой дополнительно ввести АО, то интенсивность окисления полимера в этом слое снизится, а поступление кислорода вглубь образца, наоборот, возрастёт.

Приведенный выше краткий обзор литературных данных показывает, насколько сложным и непредсказуемым может быть физическое поведение АО и как сильно оно может отражаться на эффективности ингибитора. По-видимому, еще длительное время главные успехи в области термоокислительной стабилизации полимеров будут проистекать из результатов исследований, полученных для конкретных парных сочетаний полимеров и АО.

В данной работе на примере композиции полиэтилена с ирганоксом 1010 ставится задача определить аналитические возможности ИКспектроскопии по оценке распределения ингибирующей добавки в объеме образца, а также особенности поведения АО при прямом и обратном переходе полимера через температуру плавления полимера. В такой постановке эта задача базируется на том, что в исследованиях российских ученых [21] была показана принципиальная возможность применения ИКспектроскопии пропускания с этой целью. Необходимы конкретные исследования.

\section{Материалы и методы исследований}

В качестве основного объекта исследований использовался порошкообразный нестабилизированный полиэтилен низкого давления (ГОСТ 16338-85, марка 20308-005), в который вводили фенольный АО ирганокс 1010 (4-оки-3,5-ди-трет-бутилпропионовой кислоты пентаэритриновый эфир). На рисунке 1(a) представлена химическая структура двух молекул АО (молекулы разделены пунктирной линией), каждая из которых содержит четыре гидроксильные группы, присоединённые к бензольному кольцу (фенольные гидроксилы), и четыре карбонильные группы, входящие в состав сложноэфирных группировок (рис. 1, а).

Структура молекулы АО также включает трет-бутил-радикалы, расположенные в ортоположениях относительно фенольных гидроксидов. Эти разветвленные алкильные радикалы экранируют гидроксиды, защищая их от слишком быстрой потери водорода, то есть способствуют уменьшению излишних потерь АО.

При подготовке полимерных образцов пленок требуемой толщины вначале получали смеси полимера с АО. Для этого порошок полиэтилена смачивали раствором АО в ацетоне, а затем жидкую смесь высушивали на воздухе до полного удаления растворителя. После производили окончательное перемешивание сухой смеси. В результате образовывалась механическая смесь полимера с АО, в которой вводимый модификатор был осажден на поверхности частиц полимерного связующего. Из смеси полимера с АО методом термического прессования получали пленки - образцы, которые использовали в исследованиях. Температура прессования составляла $150^{\circ} \mathrm{C}, \quad$ a 


\begin{tabular}{|c|c|c|c|c|c|c|}
\hline Impact Factor: & $\begin{array}{l}\text { ISRA (India) } \\
\text { ISI (Dubai, UAE } \\
\text { GIF (Australia) } \\
\text { JIF }\end{array}$ & $\begin{array}{l}=1.344 \\
=0.829 \\
=0.564 \\
=1.500\end{array}$ & $\begin{array}{l}\text { SIS (USA) } \\
\text { PИНЦ (Russia) } \\
\text { ESJI (KZ) } \\
\text { SJIF (Morocco) }\end{array}$ & $\begin{array}{l}=0.912 \\
=0.234 \\
=1.042 \\
=2.031\end{array}$ & $\begin{array}{l}\text { ICV (Poland) } \\
\text { PIF (India) } \\
\text { IBI (India) }\end{array}$ & $\begin{array}{l}=6.630 \\
=1.940 \\
=4.260\end{array}$ \\
\hline
\end{tabular}

продолжительность выдержки в прессе варьировали от 30 до 600 секунд.

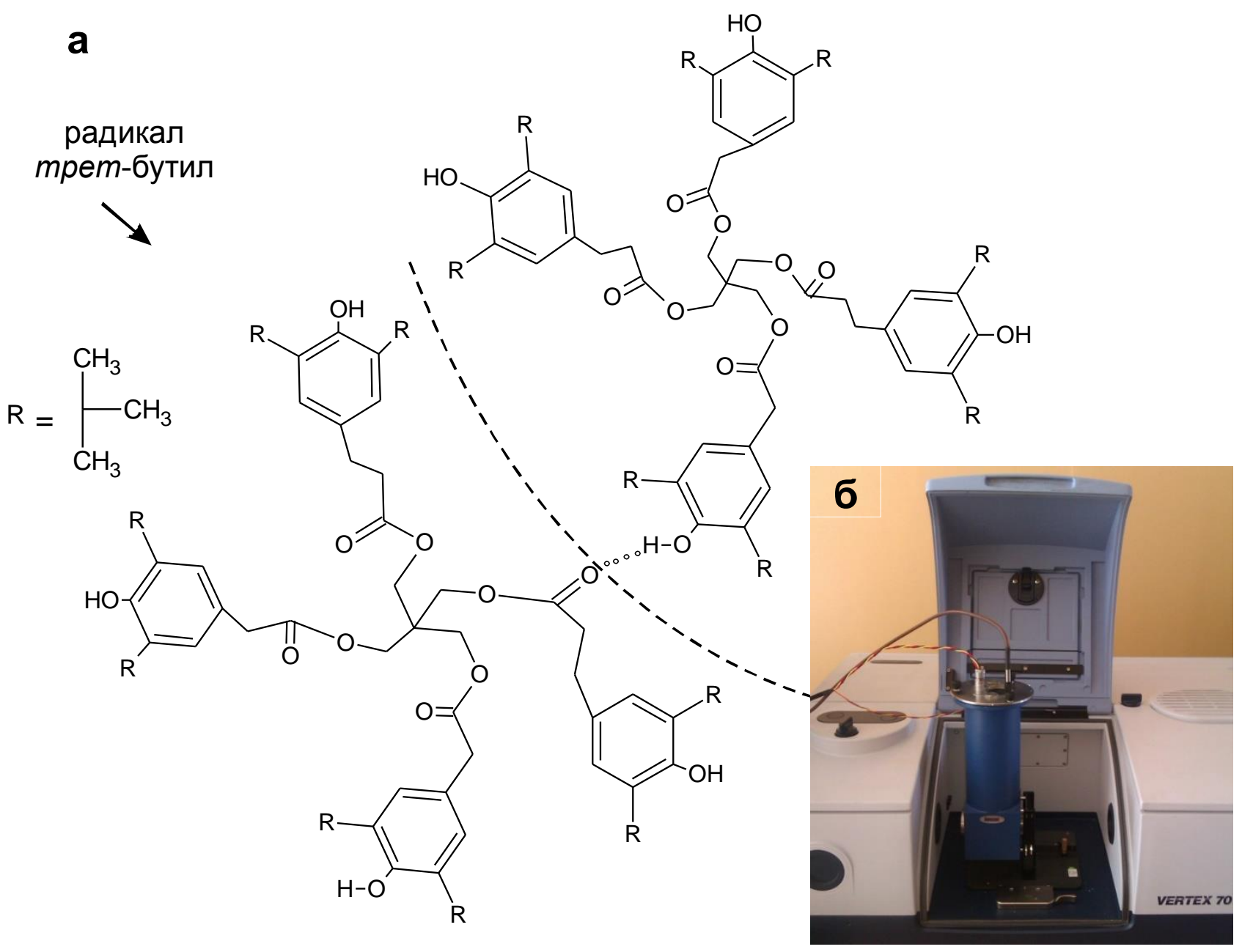

Рисунок 1 - а) Схематичное изображение двух молекул АО ирганокса 1010, связанных межмолекулярной водородной связью;

б) фото термостатирующей приставки в кюветном отделении Фурье-спектрофотометра.

В исследованиях изучали физическое поведение АО, используя для этого метод ИКспектроскопии. В экспериментах использовали либо свободные ингибированные пленки (при этом спектры снимали с образцов, имеющих температуру более низкую, чем температура плавления полиэтилена), либо пленки, находящиеся в расплавленном состоянии на подложках из КВr. В последнем случае использовали термостатирующую приставку $\mathrm{P} / \mathrm{N}$ 21525 (рис. 1,б), входящую в комплект ИКФурье-спектрометра Vertex 70 (фирма Brüker, Германия), температура регулировалась с помощью термоконтролера West 6100. Спектры снимали во время термоиспытаний (диапазон от 20 до $150^{\circ} \mathrm{C}$ ) в режиме in situ, то есть без извлечения образца из приставки.

Для анализа ИК-спектров пленок ингибированного полиэтилена использовали четыре полосы поглощения - две относящиеся к $\mathrm{AO}$, и две - к полимеру. Общий вид спектров образцов при различных температурах представлен на рисунке 2. Остановимся вначале только на ИК-спектрах, снятых при температуре $20^{\circ} \mathrm{C}$. Первая полоса поглощения, относящаяся к $\mathrm{AO}$, находится в области $3600 \mathrm{~cm}^{-1}$ (рис. 2, г). Она имеет сложную форму и в ней можно выделить два пика (А - низкочастотный, Б высокочастотный), относящихся к валентным колебаниям водорода в составе гидроксильных групп (-O-H). Вторая полоса поглощения, связанная с АО, имеет максимум в области 1745 $\mathrm{cm}^{-1}$ (рис. 2, а), и она обусловлена поглощением карбонильных групп, $>\mathrm{C}=\mathrm{O}$, входящими в молекулярный состав ингибитора [22]. Частотные границ поглощения приведены в таблице 1. О количестве $\mathrm{AO}$ в образце судили по площади названных полос поглощения, а сам расчет 
площадей вели по методу базовой линии, используя для этого стандартный пакет программ OPUS 5.5 для Фурье-спектрофотометра.

Как уже отмечалось, для анализа ИКспектров использовали также две полосы поглощения, относящиеся непосредственно к полимерной матрице. Это полосы с пиками, приходящимися на 2019 и 1984 cм$^{-1}$. Полоса 2019 $\mathrm{cm}^{-1}$ характеризует толщину образца [23], по интенсивности полосы $1894 \mathrm{~cm}^{-1}$ можно судить о степени закристаллизованности (уровне кристалличности) полимера [24, 25]. При переводе твердого полимера в расплавленное состояние поглощение в области $1894 \mathrm{~cm}^{-1}$ исчезает практически полностью (рис. 2, б).

В процессе исследований использовали два вида показателей -абсолютные и относительные. Абсолютными показателями являлись значения площадей поглощения, выбранных для анализа. По смыслу численные значения площадей полос поглощения $\mathrm{S}_{3640}$ и $\mathrm{S}_{1745}$ представляли собой величины пропорциональные суммарному количеству гидроксильных и карбонильных групп, содержащихся в антиокислительной добавке. Абсолютный показатель $\mathrm{S}_{2019}$ был пропорционален толщине пленки образца и, наконец, показатель $S_{1894}$ явился характеристикой массового содержания в образце кристаллитной фазы.

Абсолютные показатели использовали для нахождения других характеристик относительных коэффициентов. Их находили как отношение площади исследуемой полосы поглощения к площади полосы поглощения, принятой за базовую. В работе использовали четыре относительных коэффициента.

Коэффициент $K_{I}=\frac{S_{3640}}{S_{2019}}$ выражал собой концентрационную

характеристику гидроксильных групп АО в объеме образца. Соответственно, второй показатель, $K_{I I}=\frac{S_{1745}}{S_{2019}}$ выражал усредненную концентрацию карбонильных групп, входящих в состав ингибирующей добавки. Коэффициент $K_{I I I}=\frac{S_{3640}}{S_{1745}}=\frac{K_{I}}{K_{I I}} \quad$ выражал $\quad$ долю гидроксильных групп по отношению к карбонильным в составе АО фиксируемого в ИКспектрах и свидетельствовал об уровне поврежденности ингибитора, т.е. об уровне его расходования. Известно $[1,2]$, что фенольные $\mathrm{AO}$, имеющие подвижный водород в составе гидроксильной группы, уже на стадии индукционного периода реагируют с полимерными радикалами, ведущими цепи окисления. В результате водород от гидроксильной группы отрывается, окислительные цепи обрываются, а молекула АО превращается в малоактивный радикал.

$\begin{array}{crr}\text { По аналогии } & \text { четвертый } & \text { показатель } \\ K_{I V}=\frac{S_{1894}}{S_{2019}} & \text { представлял } & \text { степень }\end{array}$ закристаллизованности полиэтилена. Как уже отмечалось, при переходе полимера в расплав полоса поглощения $1894 \mathrm{~cm}^{-1}$ исчезает полностью, то есть коэффициент $\mathrm{K}_{\mathrm{IV}}$ становится равным нулю. В дальнейшем, при представлении результатов работы мы будем придерживаться введенных обозначений коэффициентов: $\mathrm{K}_{\mathrm{I}}$, $\mathrm{K}_{\mathrm{II}}$, $\mathrm{K}_{\text {III, }} \mathrm{K}_{\mathrm{IV}}$.

Диапазоны частот полос поглощения, используемых для анализа, а также рассчитываемые абсолютные и относительные показатели.

\begin{tabular}{|c|c|c|c|c|}
\hline $\begin{array}{l}\text { Положение пиков } \\
\text { аналитических } \\
\text { полос поглощения } \\
\text { в ИК-спектрах } \\
\text { образцов }\end{array}$ & $\begin{array}{c}3640 \text { см }^{-1} \\
\text { (валентные } \\
\text { колебания О-Н в } \\
\text { структуре АO) }\end{array}$ & $\begin{array}{c}1745 \mathrm{~cm}^{-1} \\
\text { (валентные } \\
\text { колебания } \mathrm{C}=\mathrm{O} \text { в } \\
\text { структуре } \mathrm{AO} \text { ) }\end{array}$ & $\begin{array}{c}2019 \mathrm{~cm}^{-1} \\
\text { (характеризует } \\
\text { толщину пленки } \\
\text { композита) }\end{array}$ & $\begin{array}{c}1894 \mathrm{~cm}^{-1} \\
\text { (характеризует } \\
\text { степень закристал- } \\
\text { лизованности } \\
\text { полимера) }\end{array}$ \\
\hline $\begin{array}{lr}\text { Частотные } & \\
\text { диапазоны полос, } \\
\text { используемые для } \\
\text { расчета } \\
\text { площадей }\end{array}$ & $3730-3530 \mathrm{~cm}^{-1}$ & $1785-1660 \mathrm{~cm}^{-1}$ & $2080-1980 \mathrm{~cm}^{-1}$ & $1850-1980 \mathrm{~cm}^{-1}$ \\
\hline $\begin{array}{l}\text { Абсолютные } \\
\text { показатели } \\
\text { площади } \\
\text { поглощения, } \\
\text { полн.ед. }\end{array}$ & $\overline{\mathrm{S}_{3640}}$ & $\overline{\mathrm{S}_{1745}}$ & $\overline{\mathrm{S}_{2019}}$ & $\overline{\mathrm{S}_{1894}}$ \\
\hline
\end{tabular}




\begin{tabular}{|c|c|c|c|c|c|c|}
\hline Impact Factor: & $\begin{array}{l}\text { ISRA (India) } \\
\text { ISI (Dubai, UAE } \\
\text { GIF (Australia) } \\
\text { JIF }\end{array}$ & $\begin{array}{l}=1.344 \\
=0.829 \\
=0.564 \\
=1.500\end{array}$ & $\begin{array}{l}\text { SIS (USA) } \\
\text { PUHЦ (Russia) } \\
\text { ESJI (KZ) } \\
\text { SJIF (Morocco) }\end{array}$ & $\begin{array}{l}=0.912 \\
=0.234 \\
=1.042 \\
=\mathbf{2 . 0 3 1}\end{array}$ & $\begin{array}{l}\text { ICV (Poland) } \\
\text { PIF (India) } \\
\text { IBI (India) }\end{array}$ & $\begin{array}{l}=6.630 \\
=1.940 \\
=4.260\end{array}$ \\
\hline
\end{tabular}

\begin{tabular}{|c|c|c|c|c|}
\hline $\begin{array}{l}\text { Относительные } \\
\text { показатели или } \\
\text { коэффициенты }\end{array}$ & $\begin{array}{c}\mathrm{K}_{\mathrm{I}} \\
\mathrm{K}_{\mathrm{I}}=\mathrm{S}_{3640} / \mathrm{S}_{2019} \\
\text { (концентрация } \\
\text { гидроксильных } \\
\text { групп) }\end{array}$ & $\begin{array}{c}\mathrm{K}_{\mathrm{II}} \\
\mathrm{K}_{\mathrm{II}}=\mathrm{S}_{1745} / \mathrm{S}_{2019} \\
\text { (концентрация } \\
\text { карбонильных } \\
\text { групп) }\end{array}$ & $\begin{array}{c}\mathrm{K}_{\mathrm{III}} \\
\mathrm{K}_{\mathrm{III}}=\mathrm{K}_{\mathrm{I}} / \mathrm{K}_{\mathrm{II}} \\
\text { (концентрация } \\
\text { гидроксильных } \\
\text { групп по } \\
\text { отношению к } \\
\text { карбонильным) }\end{array}$ & $\begin{array}{c}\mathrm{K}_{\mathrm{IV}} \\
\mathrm{K}_{\mathrm{IV}}=\mathrm{S}_{1894} / \mathrm{S}_{2019} \\
\text { (показатель } \\
\text { закристалли- } \\
\text { зованности } \\
\text { полимера) }\end{array}$ \\
\hline
\end{tabular}

Результаты экспериментов и их обсуждение

Уже в первых испытаниях, проведенных нами, выяснилось, что зависимости коэффициентов $\mathrm{K}_{\mathrm{I}}$ и $\mathrm{K}_{\mathrm{II}}$ от концентрации введенного в полимер АО является маловыразительными и линейная связь между параметрами по существу отсутствует. Так, при массовой концентрации ирганокса 1010 равной 1 $\%$ значения $\mathrm{K}_{\mathrm{I}}$ и $\mathrm{K}_{\mathrm{II}}$ составили 3,22 и 1,88 . Уменьшив концентрацию АО в образце в 40 раз (до $0,025 \%$ ) соответствующее значения показателей снизились только до 2,55 и 0,63 (спад составил всего 1,3 и 3,0 раза). Здесь следует заметить, что в обоих случаях режимы получения образцов были одинаковыми: толщина пленки 100 мкм, продолжительность термического прессования при температуре $150^{\circ} \mathrm{C}-50$ секунд, a ИК-спектры снимали при $20^{\circ} \mathrm{C}$, непосредственно после получения образцов.
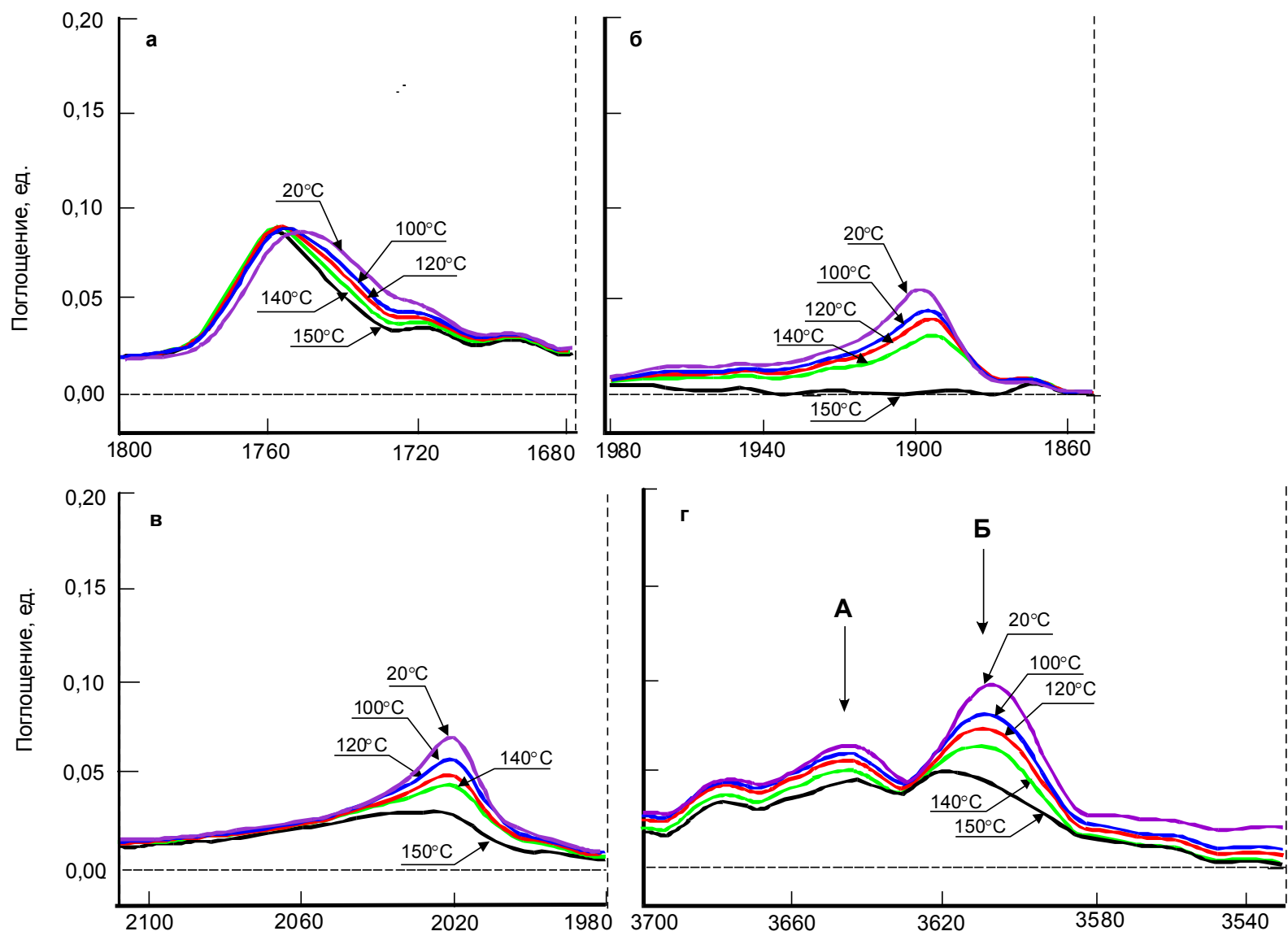

Волновое число, см ${ }^{-1}$

Рисунок 2 - ИК-спектры полиэтиленовых пленок толщиной 100 мкм, содержащих 0,1 \% масс. АО ирганокса 1010, при различных температурах кюветы (нагрев от 20 до $\left.150^{\circ} \mathrm{C}\right)$. На спектрах указана температура образца. 
Проведенный эксперимент однозначно показал, что далеко не весь введенный в образец АО фиксируется методом ИК-спектроскопии. Очевидно, что в спектрах регистрируется только часть АО, которая за время прессования образцов смогла раствориться в аморфной фазе полимера. Значительное количество АО продолжало оставаться в дисперсной фазе на местах бывших границ межпорошкового контакта. Этот результат соответствует данным работы [26], в которой утверждается, что АО в полимере находится в двух состояниях в виде нерастворимой (дисперсной) и растворимой частей. Нерастворимую часть образует АO, неуспевший раствориться или избыточный к порогу его растворимости в полимере, и эта часть выполняет роль своеобразного резервуара, пополняющего убытки АО, сорбированного полимером. АО из сорбированной части может расходоваться как на испарительные потери, так и на участие в подавлении окислительных процессов.

Стационарное распределение между растворимой и нерастворимой частями $\mathrm{AO}$ устанавливается постепенно, так как требуется время для диффузного переноса и полного насыщения ингибитором аморфной фазы образца. Отсюда понятно, что увеличивая продолжительность прессования образцов, мы могли бы ожидать увеличения концентрации АО, фиксируемого методом ИК-спектроскопии.

На рисунке 3 приведены зависимости коэффициентов $\mathrm{K}_{\mathrm{I}}$ и $\mathrm{K}_{\mathrm{II}}$ от продолжительности прессования образцов. Как видно, численные значения коэффициентов непрерывно нарастают, но скорости роста оказались различными. Так, при увеличении времени прессования с 50 до 550 секунд концентрация АО в образце, оцениваемая по количеству карбонильных групп коэффициент $\mathrm{K}_{\mathrm{II}}$, увеличивается более, чем в 10 раз - с 0,70 до 7,56. В этих же условиях, коэффициент $\mathrm{K}_{\mathrm{I}}$, характеризующий концентрацию АО в образце по количеству гидроксильных групп, увеличился всего в 1,3 раза - с 2,55 до 3,21. Этот факт, бесспорно, указывает на то, что в условиях диффузного перемещения и насыщения расплава полимера AO происходит частичное разрушение ингибитора, что проявляется в уменьшении относительной концентрации гидроксильных групп.

Подтверждение сказанному можно видеть по графику зависимости коэффициента $\mathrm{K}_{\text {III }}$ от продолжительности прессования образцов (рис. 3, кривая 3). В пределах выбранной продолжительности прессования (от 50 до 550 секунд) показатель $\mathrm{K}_{\text {III }}$, характеризующий относительную долю гидроксильных групп в общем составе сорбированного АО, снизился почти в 8,5 раза. Таким образом, фенольный АО подвержен разрушению даже в условиях ограниченного поступления кислорода в расплав полимера - при прессовании образца. Очевидно, что такое же разрушение ингибитора будет происходить на стадии получения изделий при экструзионном перемешивании расплава полимера. Чем дольше будет продолжаться перемешивание в экструдере, тем более высокой окажется не только концентрация поглощенного полимером АО, но степень его повреждения, оцениваемая с позиции содержания гидроксильных групп.

Использование приставки, входящей в комплект Фурьеспектрометра, позволяет без изменения положения исследуемого образца, то есть в режиме in situ, снимать ИК-спектры при разных температурах. Такие спектры, полученные при нагреве образца, приведены на рисунке 2 (температура указана на спектрах). Как видно, с ростом температуры образца форма полос поглощения меняется, и эти изменения в большей мере затрагивают полосу поглощения, относящуюся к гидроксильным группам (рис. 2, г). При $20{ }^{\circ} \mathrm{C}$ эта полоса представляет два пика поглощения - один в области $1645 \mathrm{~cm}^{-1}$, второй около $3605 \mathrm{~cm}^{-1}$. Такая форма полосы поглощения, относящейся к гидроксильным группам, говорит об одновременном существовании свободных колебаний водорода в составе гидроксильной группы молекулы АО (в высокочастотной области - А) и о связанных колебаниях водорода в гидроксильной группе изза образования водородных связей (в низкочастотной области -Б). Водородная связь образуется между гидроксильными группами и карбонильными группами, входящими в состав AO (рис. 2, а). Последнее подтверждает смещение ветви поглощения в области колебаний карбонильных групп (1745 $\left.\mathrm{cm}^{-1}\right)$ в сторону меньших частот. В спектрах, снятых при $20{ }^{\circ} \mathrm{C}$, такие смещения являются максимальными. Далее с ростом температуры образца степень смещения ветви снижается. Для молекул АО, вводимых в полиэтилен, возникающие водородные связи, могут быть как внутримолекулярными, так и межмолекулярными. Для выяснения характера водородных связей необходимы дополнительные исследования и в данной работе эта тема не обсуждается. 


\begin{tabular}{l|lrl|l|ll} 
& ISRA (India) & $=\mathbf{1 . 3 4 4}$ & SIS (USA) & $=\mathbf{0 . 9 1 2}$ & ICV (Poland) & $=\mathbf{6 . 6 3 0}$ \\
Impact Factor: & ISI (Dubai, UAE) $=\mathbf{0 . 8 2 9}$ & PVHIL (Russia) $=\mathbf{0 . 2 3 4}$ & PIF (India) & $=\mathbf{1 . 9 4 0}$ \\
& GIF (Australia) & $\mathbf{0 . 5 6 4}$ & ESJI (KZ) & $=\mathbf{1 . 0 4 2}$ & IBI (India) & $\mathbf{4 . 2 6 0}$
\end{tabular}

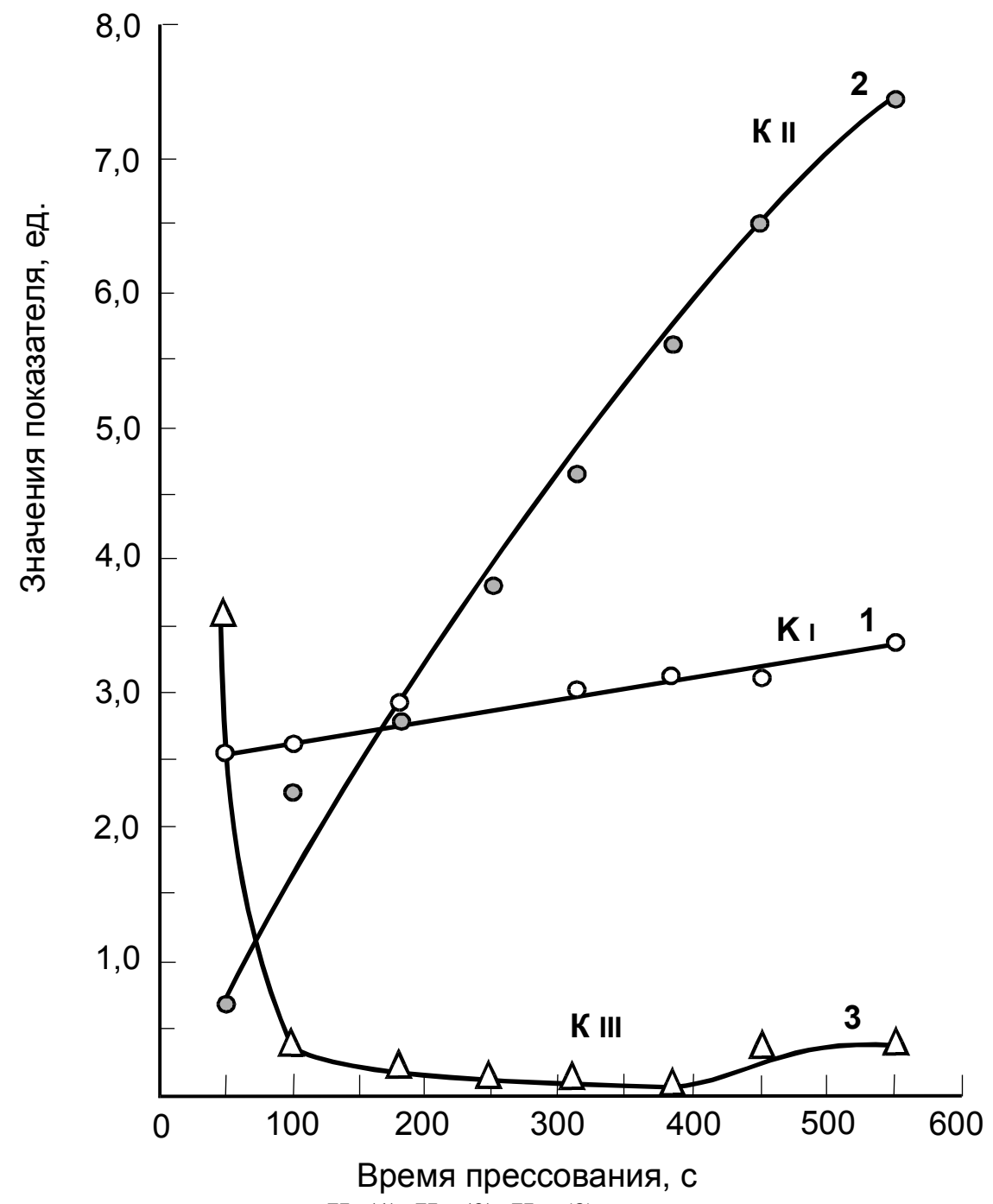

Рисунок 3 - Зависимость показателей $\mathrm{K}_{\mathrm{I}}(1), \mathrm{K}_{\mathrm{II}}(2), \mathrm{K}_{\text {III }}(3)$ в пленках полиэтилена толщиной 100 мкм, содержащих 0,1\% масс. ирганокса 1010, от продолжительности прессования образцов при температуре $150^{\circ} \mathrm{C}$. ИК-спектры пленок снимали при комнатной температуре после их получения

С повышением температуры образца (от 20 до $150^{\circ} \mathrm{C}$ ) спектральные проявления водородных связей меняются. Уменьшается интенсивность и площадь низкочастотного пика поглощения гидроксильных групп (рис. 2, г). Для полосы, относящейся к карбонильным группам, увеличение температуры образца приводит соответственно к уменьшению интенсивности поглощения в низкочастотной области спектра. Такое положение согласуется с работой [27], в которой утверждается что, при вступлении карбонильной группы в водородную связь частота валентных колебаний связи $\mathrm{C}=\mathrm{O}$ смещается на 5-25 см ${ }^{-1}$ в сторону меньших волновых чисел. На рисунке 1 схематично представлены химические структуры двух молекул ирганокса 1010, соединенных водородной связью. Можно также заметить, что образование водородных связей между соседними молекулами АО является одной из главных причин снижения диффузной подвижности изучаемого ингибитора в закристаллизованных полимерах.

Увеличение температуры образца также приводит к изменению формы и положения полос поглощения, относящихся к структуре полимерной матрицы (рис. 2, б, в). Полоса поглощения характеризующая уровень закристаллизованности полиэтилена (пик в области $\left.1894 \mathrm{~cm}^{-1}\right)$, убывает особенно интенсивно при температуре превышающей $100{ }^{\circ} \mathrm{C}$ и при 150 ${ }^{\circ} \mathrm{C}$ поглощение в этой области спектра практически исчезает (рис. 2, б). Схожее изменение происходит и для полосы поглощения в области $2019 \mathrm{~cm}^{-1}$ - с ростом температуры (особенно в области $140-150^{\circ} \mathrm{C}$ ) площадь полосы уменьшается (рис. 2, в).

Описанные выше изменения ИК-спектрах, происходящие при нагреве образцов носят обратимый характер. Другими словами, обратный перевод ингибированного полиэтилена из 
расплавленного в твердое состояние восстанавливает картину ИК-спектров образцов до исходной, то есть той, которой была до нагрева. Этот вывод следует из результатов следующего эксперимента.

Образец полиэтилена с общей концентрацией введенного $\mathrm{AO} \quad 0,1 \quad \%$ масс помещали в термостатирующую приставку и, не меняя в дальнейшем его положение, подвергали трехстадийной термообработке. На первой стадии (стадия А) образец нагревали, начиная с $20^{\circ} \mathrm{C}$ до температуры $150 \quad{ }^{\circ} \mathrm{C}$. Общая продолжительность нагрева составляла 20 минут. После перехода полимера в расплав и достижения выбранной температуры начинали вторую стадию - термообработку образца на воздухе в изотермических условиях (стадия Б). Такая термообработка при $150{ }^{\circ} \mathrm{C}$ продолжалась 6,5 часов. По завершении этой стадии приставку отключали от источника питания, и образец охлаждали в естественных условиях (стадия В). На каждой из трех стадий периодически снимали ИК-спектры образца, по которым затем рассчитывали значение коэффициентов: $\mathrm{K}_{\mathrm{I}}, \mathrm{K}_{\mathrm{II}}$, $\mathrm{K}_{\text {III }}$ и $\mathrm{K}_{\mathrm{IV}}$. Данные расчетов представлены графически на рисунке 4.

Проследим за изменением коэффициентов на каждой из трех стадий термообработки образца: нагрев, изотермическая обработка на воздухе в расплавленном состоянии и охлаждение, переводящее расплав полимера в твердое состояние.

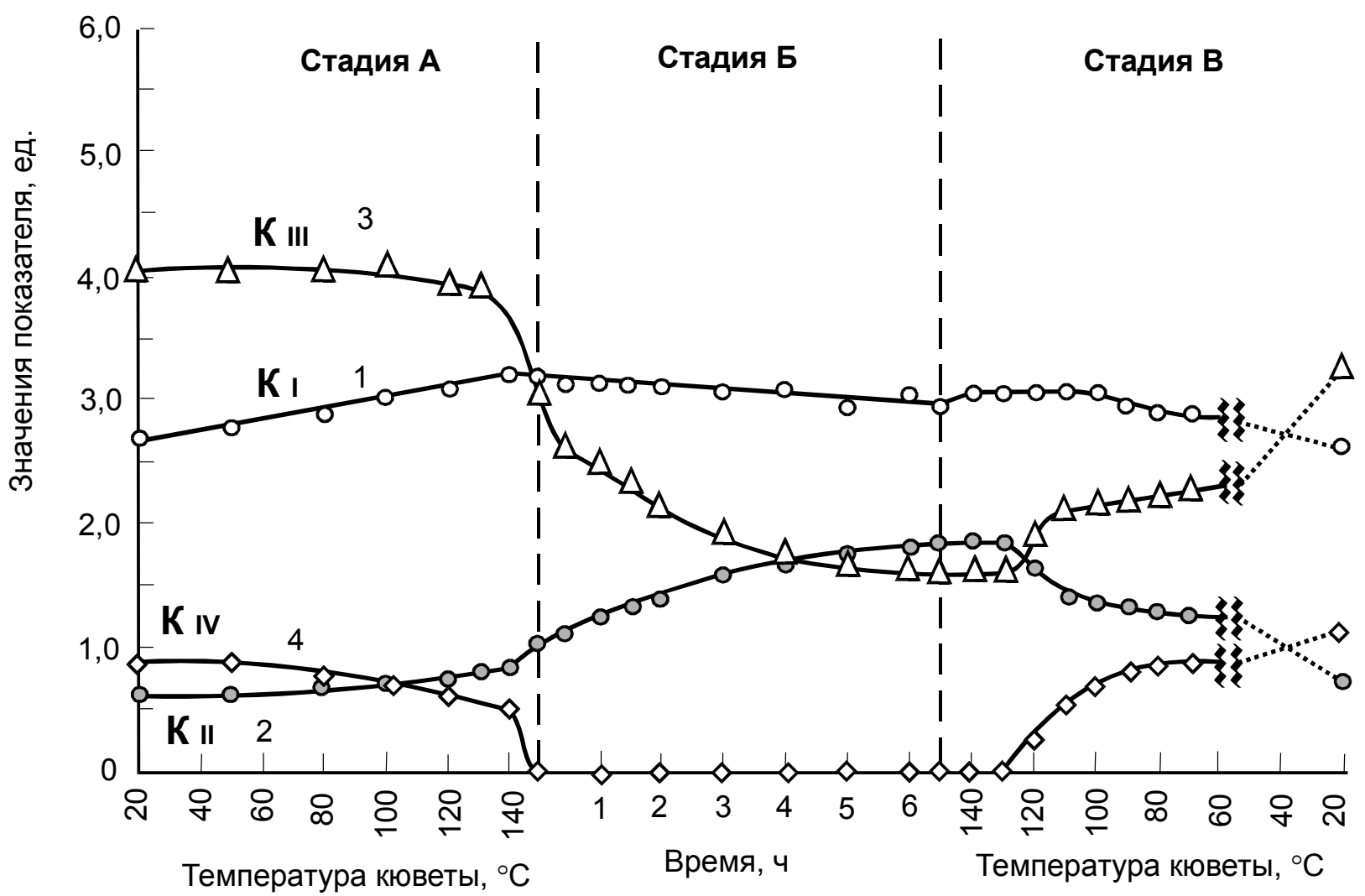

Рисунок 4 - Зависимость показателей $K_{I}(1)$, $K_{\text {II }}(2), K_{I I I}(3)$ и KVI (4) в процессе перевода образца из твердого в расплавленное состояние (нагрев - стадия А), изотермической термообработки в расплаве при $150{ }^{\circ} \mathrm{C}$ (стадия Б) и последующего перевода из расплавленного в твердое состояние (охлаждение стадия В). Исходная концентрация ирганокса 1010 в пленке $0,1 \%$ масс., продолжительность прессования 50 с, толщина образца 100 мкм.

На стадии нагрева образца коэффициенты $\mathrm{K}_{\mathrm{I}}$ и $\mathrm{K}_{\text {II }}$ постепенно нарастают (рис. 4, начальные участки кривых 1, 2), что объясняется как увеличением растворимости АО с увеличением температуры испытаний, как и с увеличением доли аморфной фазы полимера в результате плавления кристаллитов. Последнее, повидимому, обеспечивает небольшой скачок в изменении коэффициента $\mathrm{K}_{\mathrm{II}}$ в температурном диапазоне от 140 до $150{ }^{\circ} \mathrm{C}$. Об исчезновении кристаллитной структуры при нагреве образца можно судить по кривой 4 (рис. 4). Несмотря на увеличение общего количества $\mathrm{AO}$, поглощенного аморфной фазой полимера, относительная доля входящих в него гидроксильных групп (коэффициент $\mathrm{K}_{\mathrm{III}}$ ) с ростом температуры снижается (рис. 4, кривая 3). Как уже отмечалось, еще на стадии диффузионного перемещения АО происходит разрушение части гидроксильных групп. С 
переходом образца во вторую стадию термообработки, процессы, связанные с перераспределением и превращениями АО, продолжаются. Растет коэффициент $\mathrm{K}_{\mathrm{II}}$, так как AO продолжает поступать в аморфную фазу полиэтилена, образовавшуюся в результате плавления кристаллитов на стадии нагрева образца. Правда, при этом снижаются значения коэффициентов $\mathrm{K}_{\mathrm{I}}$ и $\mathrm{K}_{\mathrm{III}}$, что однозначно указывает на продолжающиеся разрушение гидроксильных групп в составе ингибитора (рис. 4, серединный участок кривых 1,3).

Прежде, чем рассматривать поведение АО на стадии охлаждения и перевода образца полимера в твердое состояние, ограничимся одним замечанием. Как показывают приведенные выше результаты исследований, гидроксильные группы, входящие в состав АO, могут участвовать в образовании водородных связей, либо, наоборот, выходить из этих связей. Кроме этого, даже в условиях ограниченного поступления кислорода, гидроксильные группы разрушаются с отщеплением водорода. Отсюда ясно, что коэффициент $\mathrm{K}_{\mathrm{I}}$, рассчитанный из площади полосы поглощения, относящейся к гидроксильным группам, является довольно ненадежной характеристикой концентрации АО в полимере. Более предпочтительным будет коэффициент $\mathrm{K}_{\mathrm{II}}$, расчет которого базируется на площади полосы поглощения карбонильных групп. Эти группы относятся только к $\mathrm{AO}$ сорбированному полимером, то есть видимому в ИК-спектрах. Однако, при этом нельзя забывать, что по истечению индукционного периода окисления количество карбонильных групп в образце начнет расти за счёт окисления полимера. Но такое опасение является напрасным, поскольку временные рамки в представляемых исследованиях значительно уже, чем величина периода индукции окисления. Индукционный период окисления полиэтилена, содержащего $0,1 \%$ ирганокса 1010 при температуре $150{ }^{\circ} \mathrm{C}$ составляет 31 час [28].

На стадии охлаждения образца концентрация АО, оцениваемая по величине коэффициента $\mathrm{K}_{\mathrm{II}}$, убывает (численные значения коэффициента меняются с 1,86 при $150{ }^{\circ} \mathrm{C}$ до 0,75 при $\left.20{ }^{\circ} \mathrm{C}\right)$. Наиболее интенсивная убыль коэффициента фиксируется, начиная с температуры $120{ }^{\circ} \mathrm{C}$ (рис. 4, кривая 2). С этого момента в полимере начинается формирование кристаллитной структуры (рис. 4, кривая 3). Данные эксперимента однозначно свидетельствуют о том, что при кристаллизации из полимера вытесняется часть поглощенного ранее АО. Он вытесняется на границу кристаллитных и надкристаллитных образований в виде отдельной дисперсной фазы и становится в «невидимым» в ИК-спектрах. На этом фоне коэффициент $\mathrm{K}_{\mathrm{I}}$ меняется относительно слабо - с 2,93 до 2,55 (рис. 4, кривая 1). Более информационной является динамика коэффициента $\mathrm{K}_{\mathrm{III}}$ - происходит нарастание показателя с 1,61 до 3,52, т.е. относительная концентрация гидроксильных групп в составе АО, растворимого в аморфной фазе полимера, увеличивается. Поэтому можно считать, что при охлаждении образца и формировании в нем кристаллитной структуры происходит одновременное снижение концентрации поглощенного полимером АО, но остающийся в полимере ингибитор является менее дефектным или разрушенным. Вполне допустимо, что на этой стадии из полимера вытесняется АО наиболее подверженный разрушению при изотермической термообработке.

\section{References:}

1. Shlyapnikov YA, Kiryushkin SG, Maryin AP (1986) Antiokislitelnaya Stabilizatsiaya Polimerov (Antioxidizing Stabilization of Polymers). Khimia, Moscow (1986) 252 p. [in Russian].

2. Grassie N (1988) Polymer Degradation and Stabilisation / N. Grassie, G. Scott.-Cambridge New York, New Rochelle Melbourne, 232 p.

3. Billingham NC (2001) The physical behavior of polymer additives. in: H. Zweifel (Ed.) In Plastics additives handbook. 5thEdition. Hanser Verlag, Munich, Germany (2001) 1018 p.

4. Lundbäck M, Hedenqvist MS, Mattozzi A, Gedde UW (2006) Migration of phenolic antioxidants from linear and branched polyethylene //Polymer Degradation and Stability. - Vol. 91, Issue 7, (2006), pp.15711580.

5. Roe RJ, Bair HE, Gieniewski C (1974) Solubility and diffusion coefficient of antioxidants in polyethylene. Journal of Applied Polymer Science, Vol. 18, Issue 3, (1974), pp.843-856.

6. Andress B, Rohl P (1981) Diffusion studies of antioxidants in polyethylene, DM. Phenomena, Whitehaven, PA, (1981), 333 p.

7. Reynier A, Dole P, Humbel S, Feigenbaum A (2000) Diffusion coefficients of additives in 


\begin{tabular}{|c|c|c|c|c|c|c|}
\hline Impact Factor: & $\begin{array}{l}\text { ISRA (India) } \\
\text { ISI (Dubai, UAF } \\
\text { GIF (Australia) } \\
\text { JIF }\end{array}$ & $\begin{array}{l}=1.344 \\
=0.829 \\
=0.564 \\
=1.500\end{array}$ & $\begin{array}{l}\text { SIS (USA) } \\
\text { PИНЦ (Russia) } \\
\text { ESJI (KZ) } \\
\text { SJIF (Morocco) }\end{array}$ & $\begin{array}{l}=0.912 \\
=0.234 \\
=1.042 \\
=\mathbf{2 . 0 3 1}\end{array}$ & $\begin{array}{l}\text { ICV (Poland) } \\
\text { PIF (India) } \\
\text { IBI (India) }\end{array}$ & $\begin{array}{l}=6.630 \\
=1.940 \\
=4.260\end{array}$ \\
\hline
\end{tabular}

polymers. I. Correlation with geometric parameters. Journal of Applied Polymer Science, Vol. 82, Issue 10, (2000), pp. 24222433.

8. Billingham NC, Calvert PD, Manke AS (1981) Solubility of phenolic antioxidants in polyolefins, J. Appl. Polym. Sci., Vol. 26, Issue 11, (1981), pp.3543.

9. Bair HE (1973) Exudation of an antioxidant additive from thin polyethylene films. Polymer Engineering \& Science Vol.13, Issue 6, (1973), pp. 435-439.

10. Yushkyavichyute SS, Shlyapnikov YA (1967) Exudation of additives from polyethylene // Plasticheskie massy № 6 (1967) pp. 65-66 [in Russian].

11. Blumberg M, Boss CR, Chien JCW (1965) Effect of volatilization of stabilizers and oxidation products on polypropylene lifetimes.J.Appl. Polym. Sci., Vol.9, №12 (1965) pp. 3837-3843.

12. Gromov GN, Piotrowski KB (1967) Relative volatility stabilizers for plastics // Chem. promyshlennost.- N 2 (1967) pp.17-18 [in Russian].

13. Shiro Matsumoto (1983) Behavior of antioxidant in polyethylene // Journal of Polymer Science: Polymer Chemistry Edition // Volume 21, Issue 2, (1983), pp. 557-564.

14. (2011) The extractability of phenolic antioxidants into water and organic solvents from polyethylene pipe materials - Part I.- K. Thörnbloma, M. Palmlöfç, T. Hjertberga // Polymer Degradation and Stability. Vol.- 96, Issue 10 (2011), pp. 1751-1760.

15. Viebke J, Hedenqvist M, Gedde UW (1996) Antioxidant efficiency loss by precipitation and diffusion to surrounding media in polyethylene hot-water pipes // Polymer Engineering \& Science Volume 36, Issue 24, (1996), pp. 28962904.

16. Limm W (1992) Effect of agitation on migration of Irganox 1010 antioxidant from polypropylene to water [Text] W. Limm, G. M. Cramer, H. C. Hollifield // Pittsburgh Conf. Presents PITTCON'92, New Orleans, La, March 9-12, 1992: Book Abstr. - [New Orleans (La)] (1992) - pp.129.

17. Gromov BA, Korduner NV, Miller VB, Shlyapnikov YA (1970) Solubility of the antioxidant in the crystalline polyethylene / Papers of USSR Academy of Sciences (DokladyAN SSSR) Vol.190, № 6 (1970) pp.1381-1382 [in Russian].

18. Rapoport HY, Shlyapnikov YA, Gromov BA, Dubincky VZ (1972) Influence of the supramolecular structure of isotactic polypropylene solubility coefficient and diffusion of antioxidants // Vysokomol. Soedin., Vol.14, №7, (1972), pp.1540-1544. [in Russian].

19. Koros WJ, Paul DR (1976) Design considerations for measurement of gas sorption in polymers by pressure decay // Journal of Polymer Science: Polymer Physics Edition.Vol. 14, Issue 10, (1976), pp. 1903-1907, DOI: $10.1002 /$ pol.1976.180141014

20. Mar'in A (1988) Additives solubility in polymers (Article) // International Journal of Polymeric Materials and Polymeric Biomaterials / Vol. 42, Issue 1-2, (1998), pp. 125-163.

21. Korotkova SD, Medvedeva CB, Morozova LG (2002) Determination of the mass concentration of stabilizers irganoks1010 and Irganox MD1024 at their joint presence in the polyethylene compositions // Chemistry and Computational Simulation. Butlerov Communications. (2002) № 8. Abstracts Volga Region Conference on Analytical Chemistry [in Russian]. Available: http://chem.kstu.ru/butlerov_comm/vol3/cda5/data/jchem\&cs/russian/n9/app19/analit2001/ pdf/1ach146.pdf (Accessed: 10.07.2016).

22. Tarutina LI, Pozdnyakova FO (1986) Spectral Analysis of Polymers. Moscow, Khimia, (1986) 248 p. [in Russian].

23. Lambert JB, Shurvell HF, Lightner DA, Cooks RG (1998) Organic Structural Spectroscopy; Prentice Hall: Upper Saddle River, (1998), pp.375.

24. Dehant I, Dants R, Kimmer V, Shmolke R (1976) Infrared spectroscopy of polymers, Khimiya, Moscow (1976) 472 p. [in Russian].

25. Lobo H (2003) Handbook of plastics analysis / H. Lobo, J. V.Bonilla. - New York: Marcel Dekker, Inc., (2003). - 656 p.

26. Richaud E, MonchyLeroy C, Colin X, Audouin L, Verdu J (2009) Kinetic modelling of stabilization coupled with stabilizer loss by evaporation. Case of dithioester stabilized polyethylene// Polymer Degradation and Stability Vol. 94, Issue 11, (2009), pp. 20042014.

27. (1966) Primenenie Molekulyarnoi Spektroskopii v Khimii (Application of Molecular Spectroscopy to Chemistry) / ed. A.V. Korshunov.- Nauka, Moscow (1966), pp, 271[in Russian].

28. Lin DG (2013) Performance of a Phenolic Antioxidant Introduced by Different Procedures into Polyethylene Containing Dispersed Fillers / D.G. Lin and E.V. Vorob'eva // Russian Journal of Applied Chemistry.- D.G. Lin and E.V. Vorob'eva.- 2013.- Vol. 86, Issue 1.- P. 82-86. 